\title{
Balanitis due to fixed eruption after Mandrax
}

\author{
G. W. CSONKA \\ From the Central Middlesex Hospital, Park Royal, London, N.W.10
}

Five cases of balanitis due to fixed eruption after tetracycline therapy were reported by Csonka, Rosedale, and Walkden (1971) and since then a severe recurrent balanitic reaction has been observed in one patient after taking single doses of 'Mandrax' (diphenhydramine-methaqualone). No similar case appears to have been published.

\section{Case report}

An unmarried Caucasian male student, aged 20, attended the special clinic in December, 1969, with severe erosive balanitis of 3 days' duration. Scrapings showed no Candida or other specific organisms and serological tests for syphilis were negative. The condition cleared completely in a week. There had been no serious illness in the past but he gave a history of urticaria which developed after treatment with systemic penicillin in childhood.

On further questioning the patient stated that the day before the onset of balanitis he had taken two tablets of Mandrax to get "high" at a party and that this same sequence of events had occurred on three previous occasions over the past 5 years. He denied having taken any other drug or alcohol and said that he had had no sexual intercourse for over a year. He presented again 4 months later with an identical episode of erosive balanitis after taking yet another two tablets of Mandrax; the condition healed in 7 or 8 days as before.

This patient had thus had a fixed eruption on the glans penis on five separate occasions within 24 hours of taking a single dose of Mandrax. He was well aware of the relationship between the drug and balanitis but considered the discomfort worth while.

\section{Discussion}

An eruption is 'fixed' if it recurs at the same site after re-exposure to the drug which precipitated the first lesion. In the literature available to us, no case of fixed eruption balanitis associated with Mandrax has been found. Mandrax and the identical Paldona contain methaqualone and diphenhydramine and in the period 1965-69 some seventy cases of various skin reactions associated with this compound have been reported to the Committee on Safety of Medicines, including one instance of a fixed drug eruption (Ruttle, 1971). Mandrax (and Paldona) are widely prescribed $(2,800,000$ prescriptions on EC 10 in 1969); the incidence of reported skin reactions is thus not excessively high.

If there is a history of repeated balanitis after taking the same drug as in the present case, the diagnosis presents no problems, but when the history is uncertain and a fixed eruption is suspected, a provocation test is of great diagnostic value. Occasionally the provoked reaction may be severe, as in one of our patients who developed extensive balanitis after penicillin given inadvertently after a lesser reaction on a previous occasion.

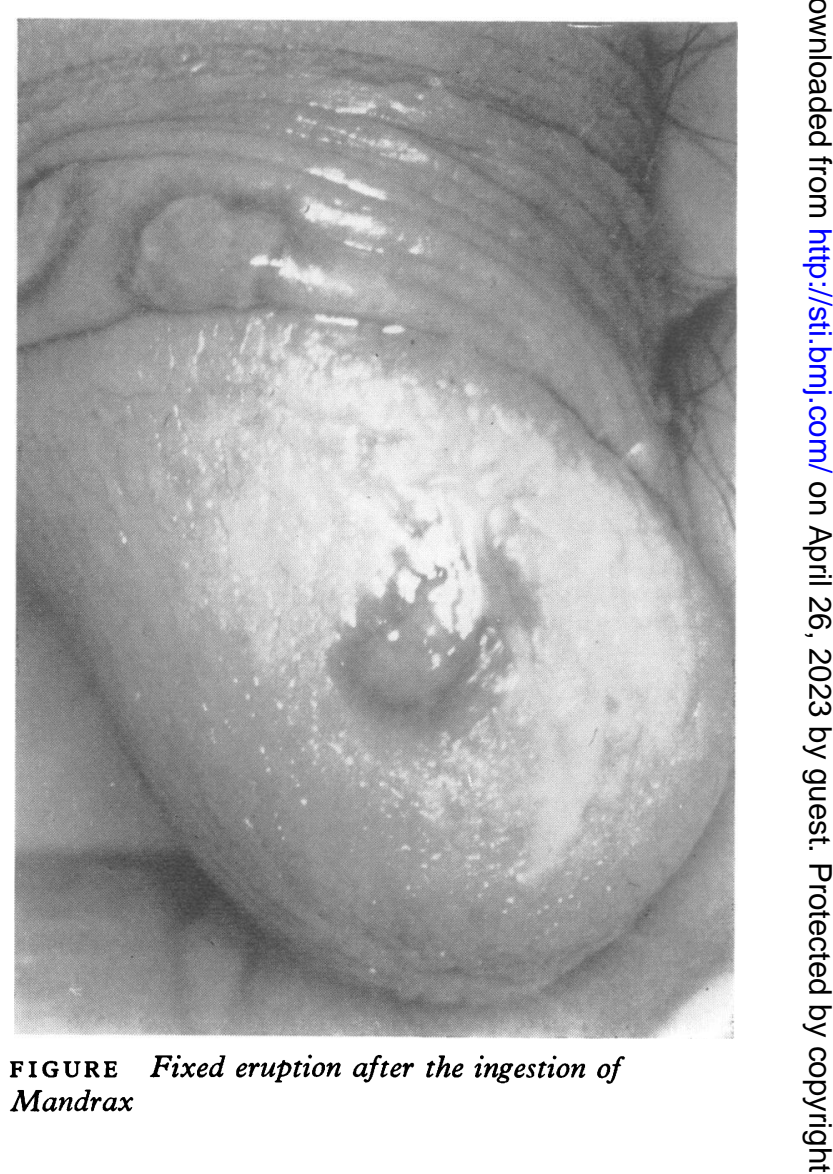


We have now seen seven cases of fixed eruption balanitis in one clinic in a period of just over one year, with five cases after tetracycline, one after systemic penicillin, and one after Mandrax. This suggests that the glans penis is not an uncommon target area for drug-induced fixed eruption, and that a variety of chemically unrelated compounds may be responsible.

\section{Summary}

A case is reported of a fixed drug eruption arising on the glans penis after self-medication with single doses of Mandrax on several separate occasions.

\section{References}

Csonka, G. W., Rosedale, N., and Walkden, L. (1971) Brit. F. vener. Dis., 47, 42

Rutre, S. (1971) Personal communication.

\section{Addendum}

After this report had been submitted a second case was seen. Both the history of repeated attacks of erosive balanitis after single doses of Mandrax and the appearances of the lesions were very similar (Figure). This patient, an addict, stated that several of his friends had experienced the same type of response to Mandrax.

Balanite due à un érythème pigmenté fixe après Mandrax

SOMMAIRE

On rapporte le cas d'un érythème pigmenté fixe d'origine médicamenteuse survenu sur le gland après auto-médication par doses uniques de Mandrax, prises de temps en temps. 